\title{
A Short Summary of My Amazing Experience at UFRGS
}

\author{
Lisa Marie Jamhoury \\ Pace University - UFRGS
}

As a Political Science major in Pace University's Honors College, I could not be happier with the experience of participating in the FIPSE-CAPES interchange program between Pace University and The Federal Univetsity of Rio Grande do Sul (UFRGS) in Porto Alegre, Brazil. During the semester long program in Fall Semester 2005 (August....December), I had many monderful cxperiences. Though it would be impossible to truly explain the generosity and kindness of the faculty and student body at UFRGS, I can at least say that they treated me with hospitality in the highest sense of the word, and assisted me with everything that I needed - from a ride to the airport, to overcoming the language barrier, to finding an apartment.

In addition, the academic atmosphere was very inspiring. In the short time that I studied at UFRGS, I was able to attend seminars by professors of vatious backgrounds and from many countries, including Argentina, Canada, and Belgium. Furthermore, I had the pleasure of accompanying Professor Claudia Lima Marques and her Research Group to the annual conference on the Consumer Code of Brazil, held in Gramado, a beautiful town in the mountains outside of Porto Alegre, and participating in the Model United Nations Conference (UFRGS MUN) in Porto Alegre in November 2005.

The conference in Gramado, a celebration of the 15 year old Consumer Code of Brazil, was a wonderful experience both culturally and academically. Duxing the conference, representatives from Brazil, Argentina, Portugal and Mexico spoke about the history, future, and importance of consumer code. Being interested in law, I found the conference very helpful and interesting. The expetience was culturally significant because I was able to see the way in which a professional conferetace is run in Brazil. I also enjoyed the beautiful mountain atmosphere of Gramado, which is reminiscent of the Swiss Alps. 
As a member of the Pace University Model United Nations (MUN) team, I thotoughly enjoyed working with the UFRGS MUN team before and during the conference. In preparation for the conference, I was able to help the staff of the conference edit background information for several committees. During the conference, I was fortunate enough to be a delegate in the Commission for Sustainable Development (CSD). The discussions during the committee were so interesting for me because they gave me the opportunity to gain an international perspective on important international issues concerning sustainable development, such as climate change and alternative energy initiatives. Most of all, the experience of working with both the staff and the delegates of UFRGS MUN gave the a fresh perspective on MUN which has given me many new and innovative tools to bring back to my team at Pace.

These experiences, coupled with the academically challenging classes in the UFRGS School of International Relations, widely broadened my view of international affairs, especially regarding international institutions, and international law. Every day of my exchange was a wonderful experience in which I learned incredibly fascinating things about the culture of Brazil and its position in the world today. Indeed, the experience was truly indispensable and I am forever indebted to the wonderful faculty and students that afforded me such an amazing opportunity. 